This PDF is a selection from an out-of-print volume from the National Bureau of Economic Research

Volume Title: Long-Range Economic Projection

Volume Author/Editor: Conference on Research in Income and Wealth

Volume Publisher: NBER

Volume ISBN: 0-691-04141-5

Volume URL: http://www.nber.org/books/unkn54-1

Publication Date: 1954

Chapter Title: Regional and National Product Projections and their Interrelations

Chapter Author: Walter Isard, Guy Freutel

Chapter URL: http://www.nber.org/chapters/c2940

Chapter pages in book: (p. 425 - 471) 
PART IV 



\title{
REGIONAL AND NATIONAL PRODUCT \\ PROJECTIONS AND THEIR INTERRELATIONS
}

\author{
W ALTER ISARD \\ MASSACHUSETTS INSTITUTE OF TECHNOLOGY
}

AND

\author{
G U Y FRE UTEL \\ WASHINGTON UNIVERSITY
}

\section{A. INTRODUCTION}

WE view the national economy as a space-economy. Resources flow from place to place and thus traverse distance as they pass through the transformation process. In contrast, general equilibrium analysis in the Walrasian tradition essentially treats a singlepoint, or nonspatial, economy. ${ }^{1}$ The same comment applies to general equilibrium analysis in the Keynesian aggregative tradition. For an insight into the operation of the economic system, nonspatial analysis at certain levels of abstraction may be useful. However, when nonspatial models (in particular, the highly aggregative models) are used as a means for understanding or projecting actual quantities, the error due solely to omission of spatial differentiation within the system may be considerable. As will be apparent later, this error is of the same type as that which may arise when aggregates, such as gross national product, national employment, and national energy requirements, are projected without attention to the interrelationships of their components. $^{2}$

The preceding statement poses the problem of choice which faces the analyst making projections of a global quantity, such as gross national product (GNP). On the one hand, he can project

Note: Many of the ideas in this paper are necessarily of an exploratory nature. The kind of regional projection discussed has been largely ignored by economists; much more analysis and subsequent modification of these ideas will be required.

1 For elaboration, see W. Isard, "The General Theory of Location and Space-Economy," the Quarterly Journal of Economics, Vol. LxII, November 1949, pp. 476-79.

2 This type of error is clearly revealed and avoided in the excellent study by Harold J. Barnett, "Energy Uses and Supplies, 1939, 1947, 1965," U.S. Bureau of Mines, Information Circular 7582, October 1950. 
the individual components of the system and their interrelations and then combine these values into a GNP. On the other hand, he can develop statistical short cuts which lean heavily on historical relationships among major aggregates, e.g., time rate of increase of average labor productivity, rate of population growth, percent of population in labor force. The GNP derived in either case is perhaps of limited interest. The difference in method is clearly brought to light by the differences in the problems faced. The analyst attempting directly to project the components must determine the degree and principle of aggregation that will reduce the number of variables and simplify his problem to the extent consistent with the degree of accuracy required. ${ }^{3}$ The analyst who directly projects GNP must select the proper historical trends and relationships. Having determined GNP, he must choose the technique of disaggregation which will yield accurate projections for the components. Whether the two methods will yield the same projections, for both GNP and its components, can be tested only by application. If they differ (and this would seem likely), the selection of procedure becomes an important issue.

A similar but somewhat more complex argument applies when we consider the space-economy. From the standpoint of the first method, a system of equations describing an economy subdivided into minute industrial categories is still not completely valid unless it recognizes spatial distinctions. A shoe factory in Tennessee is not the economic equivalent of a shoe factory in Massachusetts, even though similar in all respects except location. Hence, the interrelationships of components in an economic system should be described and constrained by a system of spatially differentiated coefficients, structurally relating the parts of the whole, and not simply by interindustry technological coefficients alone. Both the conceptual complexity and the limitations of data lead to modifications in empirical work and to a search for additional principles of aggregation.

From the standpoint of the second method (direct projection of GNP and subsequent disaggregation), consideration of the space-economy introduces a major problem. Should GNP be derived from separate regional product projections? Or should

${ }^{3}$ Accuracy in this context does not imply realized accuracy of the projections, but accuracy given the validity of the data and assumptions entering into the projection. 
regional projections be derived from GNP as simply an additional problem in disaggregation, essentially similar to disaggregation into other components of GNP? These questions will be studied in detail in later sections of the paper. The point is that, regardless of one's approach, explicit consideration of the spaceeconomy involves the aggregation or disaggregation problem.

Briefly, some spatial aggregation of economic activity is justified because it is impracticable to study the effect of distance on every individual component of the economic system. In addition, if distance acts on the distribution of economic activity to create a tendency for spatial agglomeration, we can develop principles of aggregation that will aid our analysis. Since we have viewed the economic system as a complex of production processes involving the flow of resources from place to place in the economy, we look to these flows for indications of aggregation principles.

After this introduction, it may seem inconsistent to begin with a discussion of techniques for regional projections in a one-point economy. By doing so, however, we hope to point out the limitations of such analysis, while emphasizing the need for the study of flow phenomena.

\section{B. REGIONAL PROJECTIONS DERIVED FROM GNP PROJECTION: NONINTERREGIONAL TECHNIQUES}

To derive a regional projection from a GNP projection, one might first allocate the total among regions on some proportionality basis. For example, if state $X$ produced 12 percent of the GNP in 1950, then 12 percent of the projected GNP for the year $T$ is state $X$ 's share for that date. The most immediate objection to such a procedure is the arbitrary selection of the proportionality factor. That the relative shares of the various states, or groups of states, in the GNP will remain constant over time is an unwarranted assumption. Of the many reasons to doubt the validity of such a premise, one is immediately apparent. If examination of historical ratios of gross state product (GSP) to GNP reveal changing relationships, some improvement is obtained with the use of trends. If over the past California shows an increasing proportion of GNP, extrapolation of this trend to some future date yields a better estimate of the share at that time. Since GSP and GNP are highly aggregated quantities affected by many 
factors (perhaps approaching randomness), they are, in general, fairly stable statistically. The derived relationships change fairly slowly. In general, the shorter the period of projection, the more appropriate is the use of a trend extrapolation.

There is, however, not much to justify confidence in such a procedure other than a statement about the relevance of the past to the future. It is pertinent to ask: What are the variables and relationships on which the projections of GNP are based? Would direct examination of the data for the several regions yield a different result? Examination of the technique used by the Council of Economic Advisers (CEA) to project GNP shows that they have made (1) an estimate of a rate of increase in average productivity, and (2) an estimate of the rate of population increase and labor force participation. ${ }^{4}$

On the basis of these estimates, projections of GNP are derived. Thus, with the simplifying assumption that labor force participation and number of hours worked remain constant, ${ }^{5}$ the CEA's technique becomes:

$$
\mathrm{GNP}_{t+\theta}=\mathrm{GNP}_{t}(1+p)^{\theta}(1+z)^{\theta}
$$

where $t+\theta$ refers to the projected year, $t$ refers to the current or base year, $p=$ rate of population increase, and $z=$ rate of increase in average productivity.

In the first case discussed in this section, the assumption of a constant GSP/GNP ratio meant for purposes of projection that the state parameters $p$ and $z$ were the same as those for the nation as a whole. In the second case, where a monotonically changing GSP/GNP ratio was extrapolated, an implicit assumption was made that these parameters, while different from those appropriate for the nation, ${ }^{6}$ continued to be related in a predictable fashion. We cannot ascertain by trend extrapolation whether the changing share is due to a differential in population growth, or productivity change, or both. Without this information we cannot make any statements about the reliability of trend extrapolation.

Now, if a state, say, California, has a different $p$ and $z$ from

4 See the five-year projection by the Council in the Annual Economic Review, January 1950, and "Background Material," hectographed, March 1950.

5 This assumption is maintained throughout the following discussion. It does not affect the logic of the argument.

${ }^{\circ} \mathrm{A}$ difference might be in $p, z$, or both. 


\section{REGIONAL AND NATIONAL PRODUCT}

those of the nation as a whole, then the growth of California's gross product is explained by these factors and not by the growth in GNP alone. Moreover, in reality the change in GNP is in part explained by the change in California's gross product. (This is not a complete statement, since obviously the question of the interdependence is here overlooked. But it does serve to emphasize the limitations inherent in a GNP based on extrapolated national parameters. Such a GNP becomes a quantity which can only be viewed as a statistical resultant.)

The weakness of the procedure whereby regional estimates are derived from national parameters is brought to light by the following experiment.

Equation 1

$$
\mathrm{GNP}_{t+\theta}=\mathrm{GNP}_{t}(1+p)^{\theta}(1+z)^{\theta}
$$

can be rewritten. Let

$$
\mathrm{GNP}=\Gamma \cdot L
$$

where $\Gamma=$ average labor productivity per hour, and $L=$ number of labor hours, annually.

Then

where

$$
\mathrm{GNP}_{t+\theta}=\Gamma_{t+\theta} \cdot L_{t+\theta}
$$

$$
\Gamma_{t+\theta}=\Gamma_{t}(1+z)^{\theta}
$$

and

$$
L_{t+\theta}=L_{t}(1+p)^{\theta}
$$

We take California as our region, the year 1930 as $t$, and the year 1940 as $t+\theta$.

Imagine ourselves in 1930 applying CEA techniques. Since we are not at this point discussing the CEA method per se, we assume that it is entirely valid and accurate for national projections. Thus we may use the actual 1930 to 1940 national population and productivity changes as the basis for a regional projection. If projected $\mathrm{GCP}_{1940}$ (gross California product in 1940) does not turn out to be approximately equal to actual $\mathrm{GCP}_{1040}$, then the national rates, $p$ and $z$, are inapplicable.

Using equations 3,4 , and 5 , we set up the following equation for projecting gross California product:

$$
\mathrm{GCP}_{t+\theta}={ }_{c} L_{t}(1+p)^{\theta} \cdot{ }_{0} \Gamma_{t}(1+z)^{\theta}
$$

where $\mathrm{GCP}_{t+\theta}=$ gross California product in year $t+\theta,{ }_{c} L_{t}=$ 
number of labor hours of work performed in California in year $t$, and ${ }_{c} \Gamma_{t}=$ average labor productivity per hour in California in year $t$.

However, since equation 6 assumes constant labor force participation, and since, because of unemployment, labor force participation was not the same in 1940 as in 1930, it would be wrong to use an unadjusted rate of national population growth as the value for $p$. It seems best, under these circumstances, to let $p$ represent either the rate of growth of national labor force (including unemployed) or the rate of growth of employed workers in the nation.

When we adopt the former procedure, $p=1.15$ percent per annum, and $z=0.0$ percent per annum for the period $1930-40 .^{7}$ In 1930 the labor force in California consisted of 2.5 million workers. Since in the same year gross California product $\left(\mathrm{GCP}_{\mathbf{1 9 3 0}}\right)$ may be estimated at $\$ 6.05$ billion, ${ }^{8}$ average labor productivity per worker in California in 1930 may be set at $\$ 2,421$.

Substituting these values in equation 6 , and changing the units in which ${ }_{0} L_{t}$ and ${ }_{c} \Gamma_{t}$ are expressed so that these terms represent annual labor force and average productivity per worker per year, respectively, we have:

T The average productivity estimate for any given year is derived by the simple and crude technique of dividing GNP in that year by the number in the national labor force for that year.

The zero rate of change in average productivity is primarily due to the fact that the labor force projection for 1940 includes more unemployed than the labor force in 1930. Thus, $\mathrm{GNP}_{1040}>\mathrm{GNP}_{1030 \text {, labor force }}{ }_{1040}>$ labor force 1030, unemployment ${ }_{1040}>$ unemployment ${ }_{1030}$, average product per employed worker ${ }_{1040}>$ average product per employed worker 1980, and average product per worker in the labor force ${ }_{1000}$ is approximately equal to the average product per worker in the labor force 1030 .

8 Since data on gross product for individual states are not available, an approximation had to be made. Data on income payments to individuals are published on both a national and a state basis. Accordingly, we made the assumption that the ratio of income payments to individuals to gross product for California is the same as a similar ratio for the nation. Separate ratios for 1930 and 1940 were computed and on this basis GCP estimates were derived and presumed to approximate the actual GCP's for 1930 and 1940.

The sources for our computations in this experiment were: "Unemployment," Vol. 1, 15th Census of the U.S., 1930 (Bureau of the Census, 1931), pp. 18, 19; Solomon Fabricant, "The Changing Industrial Distribution of Gainful Workers," Studies in Income and Wealth, Volume Eleven (NBER, 1949), and quoted in Historical Statistics of the United States, 1789-1945 (Bureau of the Census, 1949), p. 64; Survey of Current Business (Department of Commerce), July 1949, table 2, p. 10. 


$$
\begin{gathered}
\operatorname{GCP}_{1940}=2,500,000(1+0.0115)^{10}(\$ 2,421)(1+0.0000)^{10} \\
=\$ 6.8 \text { billion }
\end{gathered}
$$

This projected $\mathrm{GCP}_{1940}$ contrasts with the actual $\mathrm{GCP}_{1940}$, which may be estimated at approximately $\$ 7.5$ billion. The projected increment from 1930 to 1940 of $\$ 0.75$ billion contrasts with the approximate actual increment of $\$ 1.45$ billion. ${ }^{\ominus}$

In this experiment, the application of national rates $p$ and $z$ to California data for 1930 understates the actual 1930-40 increment in gross product by roughly 50 percent. Presumably this is partly the result of more rapid rates of growth in labor force or employment for California than for the nation as a whole. (The actual rates for California were 1.7 percent and 0.95 percent, respectively.) In part, the understatement can also be attributed to a more rapid rate of increase in average productivity in California. This latter can be partially explained by the increased proportion of the labor force used in high-productivity industries.

Thus on the basis of such a simple projection model, the regional implications of any projected GNP cannot be ascertained without reference to considerations internal to regions. Information about rates of growth of relevant variables pertinent to regions is required. This poses a logical problem in the selection of the proper procedure. If regional implications of national projections cannot be derived without reference to regional rates of change, and if regional rates of change can be discovered only by study of the region under consideration, is it not a superior procedure to begin operations with regional analysis and later reconcile regional projections with national projections? Indeed, this would point to a complete reversal of technique and result in the derivation of national projections from a set of mutually consistent regional projections.

We now focus attention on the possibility of projecting gross regional product (GRP) by using regional rates of change for extrapolating regional aggregates. Using the CEA methodology, we would have the following for region $i$ :

where

$$
{ }_{i} \mathrm{GRP}_{t+\theta}={ }_{i} \Gamma_{t+\theta}^{\prime} \cdot{ }_{i} L_{t+\theta}
$$

$$
{ }_{i} \Gamma_{t+\theta}={ }_{i} \Gamma_{t}(1+i z)^{\theta}
$$

${ }^{9}$ If we adopt the alternative procedure of allowing $p$ to represent the rate of growth of employed workers in the nation, the value of $p$ is then 0.45 percent per annum and that of $z$ is 0.65 percent per annum. As can be expected, the same result is obtained for projected $\mathbf{G C P}_{1040}$. 
and

$$
{ }_{i} L_{t+\theta}={ }_{\imath} L_{t}(1+\imath p)^{\theta}
$$

and where $z=$ rate of increase in average productivity in region $i$, and ${ }_{i} p=$ rate of population increase in region $i .^{10}$ From this point of view,

$$
\mathrm{GNP}_{t+\theta}=\sum_{i=1}^{i=m}{ }_{i} \mathrm{GRP}_{t+\theta}
$$

There is little reason to suppose that GNP derived in this way will be the same as GNP derived directly from projection of nationally estimated rates of change. But a difference in results does not mean that proceeding from separate regional projections and then summing to obtain the national is preferable to directly obtaining GNP, since we have at this stage taken no account of the interaction of differential regional rates of change. The GNP directly derived may be more valid than that derived by combining separately estimated GRP's. On the other hand, each of the separately derived GRP's is likely to be more valid than a GRP derived from a GNP using national coefficients of change.

\section{REGIONAL PROJECTIONS: INTERREGIONAL REACTIONS}

It is clear that growth (or decline) of the GRP of a region $i$ is not independent of the direction and rate of change of the GRP of some other region $j$. Projections of GNP based on extrapolation of past national trends implicitly take account of interregional relations. The task of regional analysis is to make such relations explicit. The simple extrapolation of a trend in the proportion "GRP/GNP relates the part to the whole without revealing the substance of the relation. Further insight is gained by directly linking growth in one region with that in another. In

${ }_{10}$ To obtain regional rates of change, we need information about the demographic characteristics and industrial structures of the several regions. For example, in estimating $p$, we must consider questions of differential fertility rates, migration, and rural-urban population shifts.

A regional $p$ or $z$ can be presumed to be less satisfactory for trend extrapolation than a national $p$ or $z$, since a region's population and industrial structure are usually subject to a greater degree of variation than those for the nation as a whole. 
a two-region economy, regional projections based on regional changes can be simply stated as:

$$
{ }_{i} \mathrm{GRP}_{t+\theta}={ }_{i} \mathrm{GRP}_{t}+\beta\left({ }_{j} \mathrm{GRP}_{t+\theta}-{ }_{j} \mathrm{GRP}_{t}\right)
$$

and

$$
{ }_{j} \mathrm{GRP}_{t+\theta}={ }_{j} \mathrm{GRP}_{t}+a\left({ }_{1} \mathrm{GRP}_{t+\theta}-{ }_{\mathrm{G}} \mathrm{GRP}_{t}\right)
$$

where the parameters $\beta$ and $a$ are determined by statistical observation. This implies mutual interaction by regions $i$ and $j$ on the rates ${ }_{j} p, j z, i p, i z$. The $p$ 's will be determined by fertility rates and migration. The $z$ 's may represent over-all increases in productivity due to (1) greater effort or education, (2) the increasing weight in the average of more highly productive occupations, i.e., a shift in industrial structure, (3) technological progress, or (4) an unknown combination of all three. Whatever the source of the changes in the $p$ 's and $z$ 's, the mutual impact is transmitted by population movements and flows of goods and services between the regions. Population movements aside, the volume and composition of the commodity flows will be determined by the industrial structures of the respective regions.

Usually, however, more than two regions must be considered, and the simple linking of growth factors is inadequate. The economic interrelations between regions depend not only on their industrial structures, but on the distance separating the regions. Presumably, distance attenuates economic relations and the impact of extraregional change. ${ }^{11}$

The effect of the spatial position of a region with respect to other regions can be introduced explicitly through the concept of income potential, which parallels Stewart's concept of population potential.12

In Stewart's terms the potential of population at any one point $A$ produced by the population $P$ at point $B$ is:

$$
{ }_{4} V_{B}=\frac{G P_{B}}{d}
$$

where $d$ is the distance separating $A$ and $B$, and $G$ is a constant. At point $A$, the total potential $\left({ }_{A} V\right)$ is the sum of the separate

11 Obviously, too, the industrial structure of a region depends in part on its distance from other regions.

12 J. Q. Stewart, "Empirical Mathematical Rules Concerning the Distribution and Equilibrium of Population," Geographical Review, Vol. xxxvII, July 1947; "Demographic Gravitation: Evidence and Applications," Sociometry, Vol. XI, February-May 1948; and "Potential of Population and Its Relationship to Marketing," Theory in Marketing (Irwin, 1950). 
potentials. When a population distribution is confined to a surface and is continuous,

$$
{ }_{4} V=\int \frac{1}{d} D d S
$$

where $D$ is the density of population over the infinitesimal area $d S$. However, since data are available only for large areal units, such as states, Stewart computes total population potential by using the following modification of equation 14:

$$
{ }_{i} V=\sum_{j=1}^{j=m} \frac{1}{d_{i j}} D_{j} \quad(i=1,2, \ldots, m)
$$

where ${ }_{i} V$ is the total population potential of state $i, D_{j}$ is the population of state $j$, and $d_{i j}$ is the distance between state $i$ and state $j .^{13}$ According to Stewart, ${ }_{i} V$ is a measure "of the influence of people at a distance." 14

We define the potential of income produced by any region $i$ on another region $i$ as

$$
{ }_{i} V_{j}=\frac{G Y_{j}}{d_{i j}} \quad(i=1,2, \ldots, m)
$$

and the income potential produced by all regions on a given region $i$ as

$$
{ }_{i} V=\sum_{j=1}^{j=m} \frac{k_{j}}{d_{i j}} Y_{j} \quad(i=1,2, \ldots, m)
$$

where $k_{j}$ is a constant, ${ }^{15}$ and $Y_{j}$ is the income of region $j$, which in our context becomes a state or group of states.

Where ${ }_{i} V$ is low, the region is presumably far from markets. Setting aside inequality of resource distribution, the region tends

13 The population of each state must be taken to be concentrated at some chosen point within it, and distances must be computed from these points of concentration. As a result, the smaller the area for which data are available, the more accurate and meaningful the computed total population potentials. To determine a value for $d_{\text {is }}$ for computing the potential produced by a state upon itself, a special procedure must be followed. See Stewart, "Empirical Mathematical Rules . . . ," op.cit.

14 "Demographic Gravitation: Evidence and Applications," op.cit., p. 35.

15 The expression $k$, may be viewed as a factor for converting actual distance into effective economic distance. It may be taken as a weighted average ratio of transport costs over a standard route to transport costs over the given routes connecting region $j$ and region $i$.

For purposes of this paper, the potential of income is inversely related to the first power of the distance variable simply to illustrate certain relationships. Empirical studies may well indicate another type of inverse relation. 


\section{REGIONAL AND NATIONAL PRODUCT}

to have few interregional relations because of the high transport costs to markets. Where ${ }_{i} V$ is high, many interrelations can be expected.

Adding to equation $1 \mathrm{a}$ term to account for interregional relations and the effect of distances separating regions, we may project regional gross product as follows:

$$
\begin{gathered}
{ }_{i} \mathrm{GRP}_{t+\theta}={ }_{i} \mathrm{GRP}_{t}(1+p)^{\theta}(1+z)^{\theta}+\beta_{i}\left[\frac{{ }_{i} V_{t+\theta}}{(1+\rho)_{i} V_{t}}-1\right]{ }_{i} \mathrm{GRP}_{t} \\
(i=1,2, \ldots, m)
\end{gathered}
$$

where $p$ and $z$ are national rates of change, as before; $\beta_{i}$ is a positive constant which for each region should vary with the character of its resources, ${ }^{16} \rho$ is the rate of change in national income; and ${ }_{i} V_{t}$ and ${ }_{i} V_{t+\theta}$ are the income potentials of region $i$ in years $t$ and $t+\theta$, respectively. According to set of equations 18 , the change in ${ }_{i} \mathrm{GRP}$ depends on internal and external changes. The effects of external changes are mitigated to the extent that they occur at a distance.

A few remarks to explain the construction of this set of equations are in order. Income potential at region $i\left({ }_{i} V_{t}\right)$ may rise simply because all regional incomes are rising. Thus, if we use just the concept of income potential in the equations, we shall be taking account of the income effect twice. For the over-all increase in incomes has already been accounted for in $p$ and $z$, the national rates of change. To avoid such double counting, we use the concept of relative income potential, ${ }_{i} V_{t+\theta} /\left[(1+\rho){ }_{i} V_{t}\right]$. When all regional incomes rise by the same percent, the relative income potential is equal to un: $y$, the second part of the set of equations 18 is zero, and each region's growth directly parallels national growth. This is what one would expect.

It is interesting to note the effects of certain changes. For example, a shift of population toward $i$ will cause ${ }_{i} V$ to rise (because of larger markets), and conversely for population shifts away from $i$. If national income rose, but population shifted away from $i$, the relative income potential would decrease (though the ratio of the income potentials need not). The second quantity to the right of the equations would become negative, thus offsetting to some extent the growth occasioned by $i$ 's share in $p$ and $z$.

${ }^{16}$ For example, a highly localized, immobile resource might tend to raise the $\beta$, for a given region. 
The value of $\beta_{i}$ to be used for projection purposes may be determined by fitting a trend line to past values for $\beta_{i}$. Past values are obtainable, since we know current and past values of $p, z$, $Y_{j}$, and ${ }_{i}$ GRP. $\beta_{i}$ represents the effects of peculiarities of regional resource structures. These modify or qualify the distance implications alone which are present in ${ }_{i} V$. The state of Washington, for example, has closer relations with the Eastern Seaboard than would be indicated by its income potential. Essentially, this is because of the nature of certain of its major resources such as hydro-power, used to produce aluminum which to a large extent is marketed in the New York City area, despite the distance factor. Projecting $\beta_{\boldsymbol{i}}$ would result in a true historical approach, comparable to projecting regional rates of growth (and making allowance for complex, but unknown, interrelations).

Thus far, we have lumped all interregional relations into one rough measure, ${ }_{i} V$. By so doing, we have an operational model in the sense that the required parameters can be statistically derived from obtainable data. Such a procedure, however, necessarily eliminates consideration of the individual regional interrelations, which are basic. A more adequate model would avoid aggregating into the single measure ${ }_{i} V$ the interregional relations modified by distance. It would consider the separate potentials produced by each region upon region $i$. The relation of each region to region $i$ might be handled through separate $\beta$ coefficients and through appropriately qualified incremental income-distance relations.

Set of equations 18 might be modified to read:

$$
\begin{gathered}
{ }_{i} \operatorname{GRP}_{t+\theta}={ }_{i} \operatorname{GRP}_{t}(1+p)^{\theta}(1+z)^{\theta}+\beta_{i j}\left(\frac{\Delta Y_{j}}{1+\rho} \cdot \frac{d}{d_{i j}}-1\right) \\
+\ldots+\beta_{i k}\left(\frac{\Delta Y_{k}}{1+\rho} \cdot \frac{d}{d_{i k}}-1\right)+\ldots \\
(i=1,2, \ldots, m)
\end{gathered}
$$

where $d$ may be taken as a standard economic distance.

In this manner, it is possible to allow for the effects upon any given region of regional differences in consumption patterns, input requirements, etc., as well as in resource structure. These differences are allowed for only in the sense that they presumably account for the derived value of the several constants $\left(\beta_{12}, \ldots\right.$, $\left.\beta_{i j}\right)$. Such a model, however, appears to be nonoperational be- 
cause of the high degree of intercorrelation among the $\beta$ coefficients and the associated statistical problems.

\section{FLOW PHENOMENA IN INTERREGIONAL ANALYSIS ${ }^{17}$}

The preceding sections have suggested statistical techniques for deriving projections of gross regional product. Attention has been focused on interregional relations without probing into the essential components, namely, the flow phenomena produced by the interrelated and varied industrial structures of the several regions. Some individuals may feel that analysis can be meaningful only when it incorporates study of such flows.

The accompanying set of charts illustrates certain aspects of these flows. These charts are taken from Professor Ullman's excellent study of the geographic patterns of commodity flows. ${ }^{18}$

Glancing through Ullman's entire collection of charts, one notes the striking differences among states in the length and intensity of flows as evidenced by the destinations of commodity shipments originating within the several states. Charts 1 and 2 show the destination of all commodities originating in Washington and Connecticut, respectively. Washington clearly serves a national market and has trade relations with many states. The market for the products of Connecticut is apparently much more limited in its spatial extent. Connecticut has direct interrelations with fewer states.

With the data aggregated into "all commodities," it is difficult to ascertain the meaning or explanation of this contrast. If we know the composition of the flows and the transport character-

${ }^{17}$ Much of the ensuing analysis has been independently anticipated in the pioneering work of Rutledge Vining, "The Region as an Economic Entity and Certain Variations to Be Observed in the Study of Systems of Regions," Papers and Proceedings of the American Economic Association, Vol. 39, May 1949; in ICC Dockets 29885 and 29886, Testimony of Rutledge Vining; and elsewhere. The implications of flow analysis have also been stressed by P. R. Crowe, "On Progress in Geography," Scottish Geographical Magazine, Vol. Lrv, 1938. Also see R. E. Dickinson, "Landscape and Society," Scottish Geographical Magazine, Vol. Lv, 1939; and G. K. Zipf, Human Behavior and the Principle of Least Effort (Addison-Wesley Press, 1949).

${ }^{18}$ E. L. Ullman et al., Maps of State-to-State Rail Freight Movement, for 13 states of the United States in 1948, mimeographed, 1951. These charts are based on the 1 percent sample of Class I railroad shipments reported to the Interstate Commerce Commission. 
REGIONAL AND NATIONAL PRODUCT

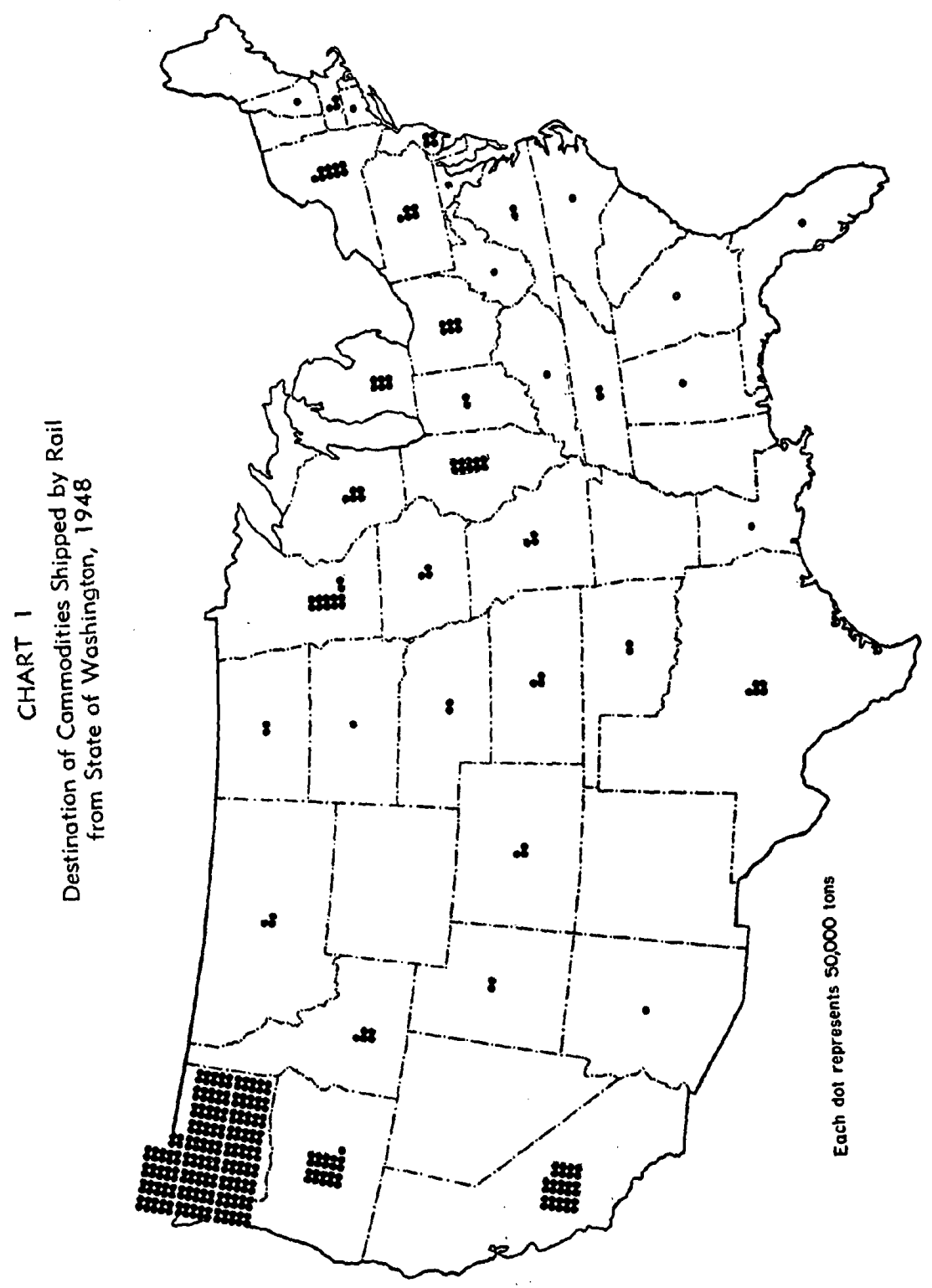


REGIONAL AND NATIONAL PRODUCT

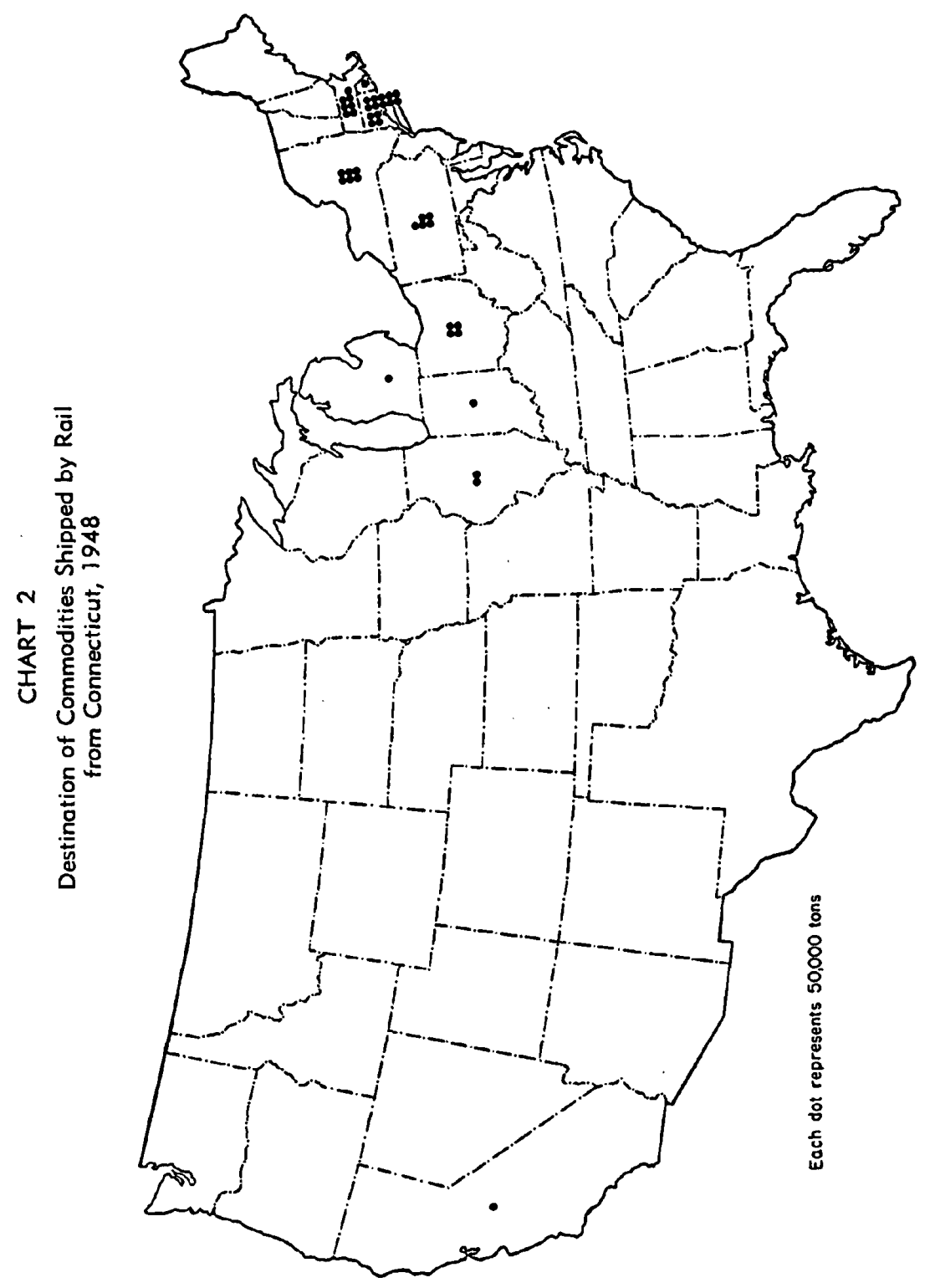


REGIONAL AND NATIONAL PRODUCT

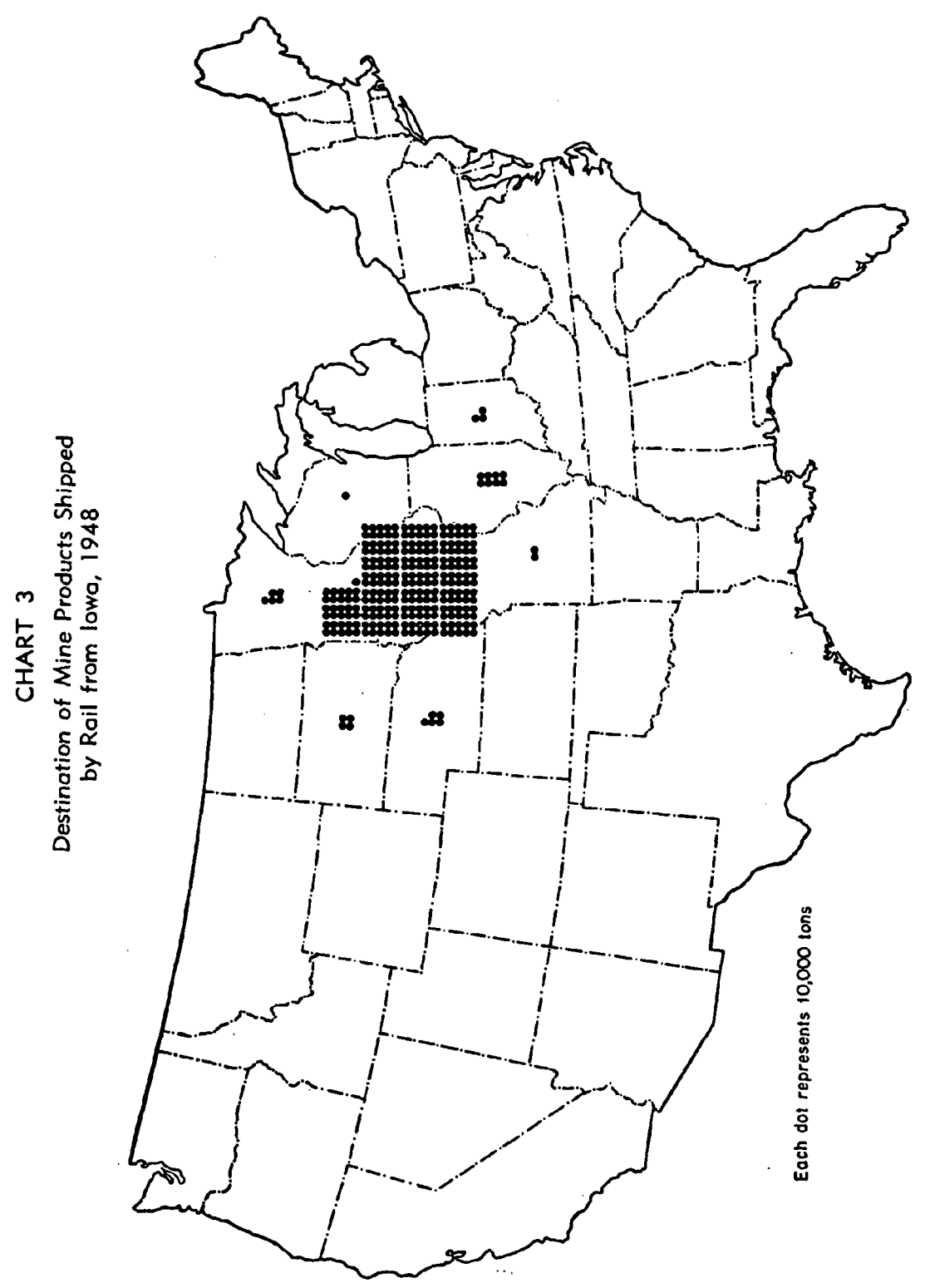


REGIONAL AND NATIONAL PRODUCT

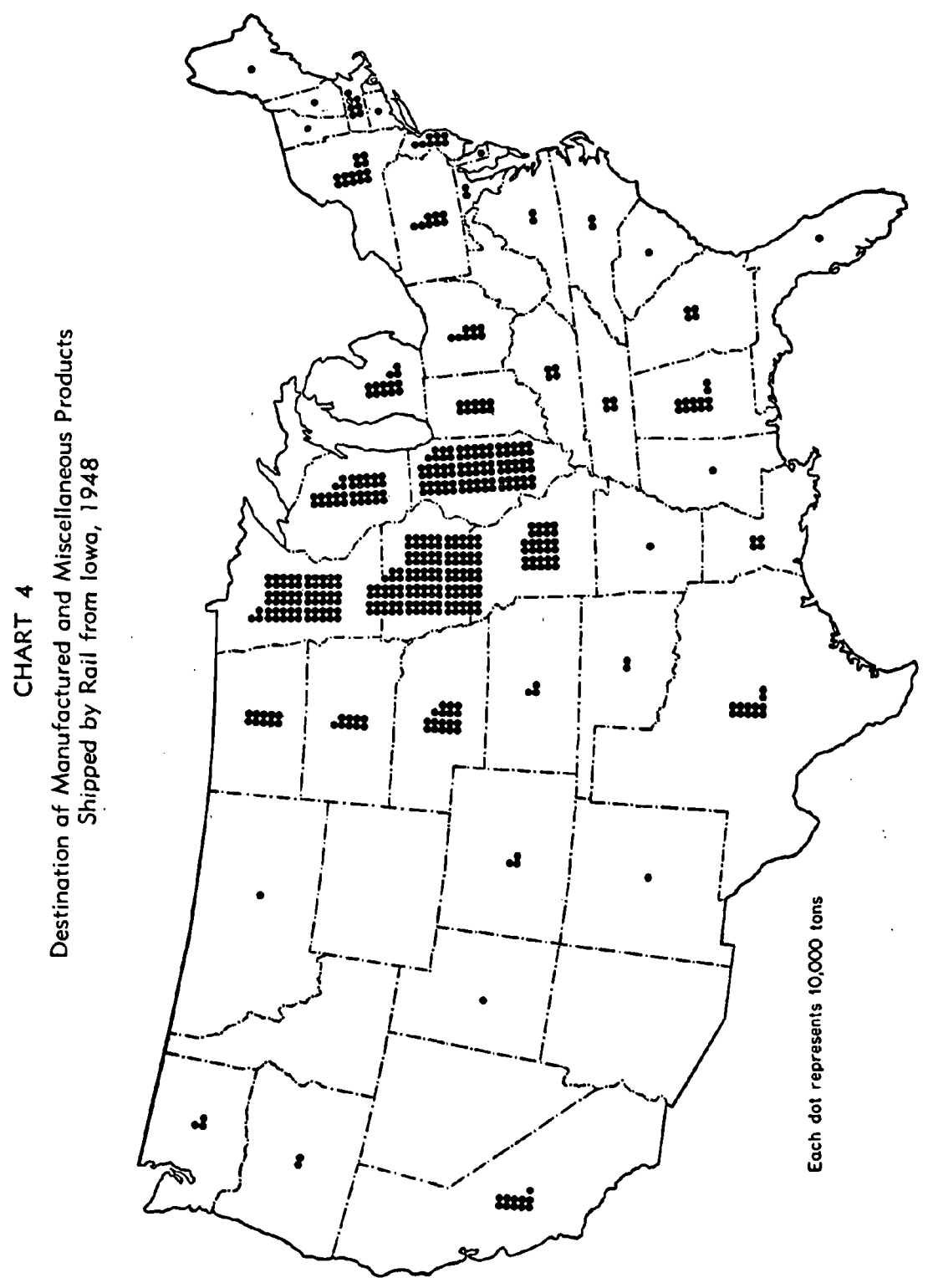


REGIONAL AND NATIONAL PRODUCT

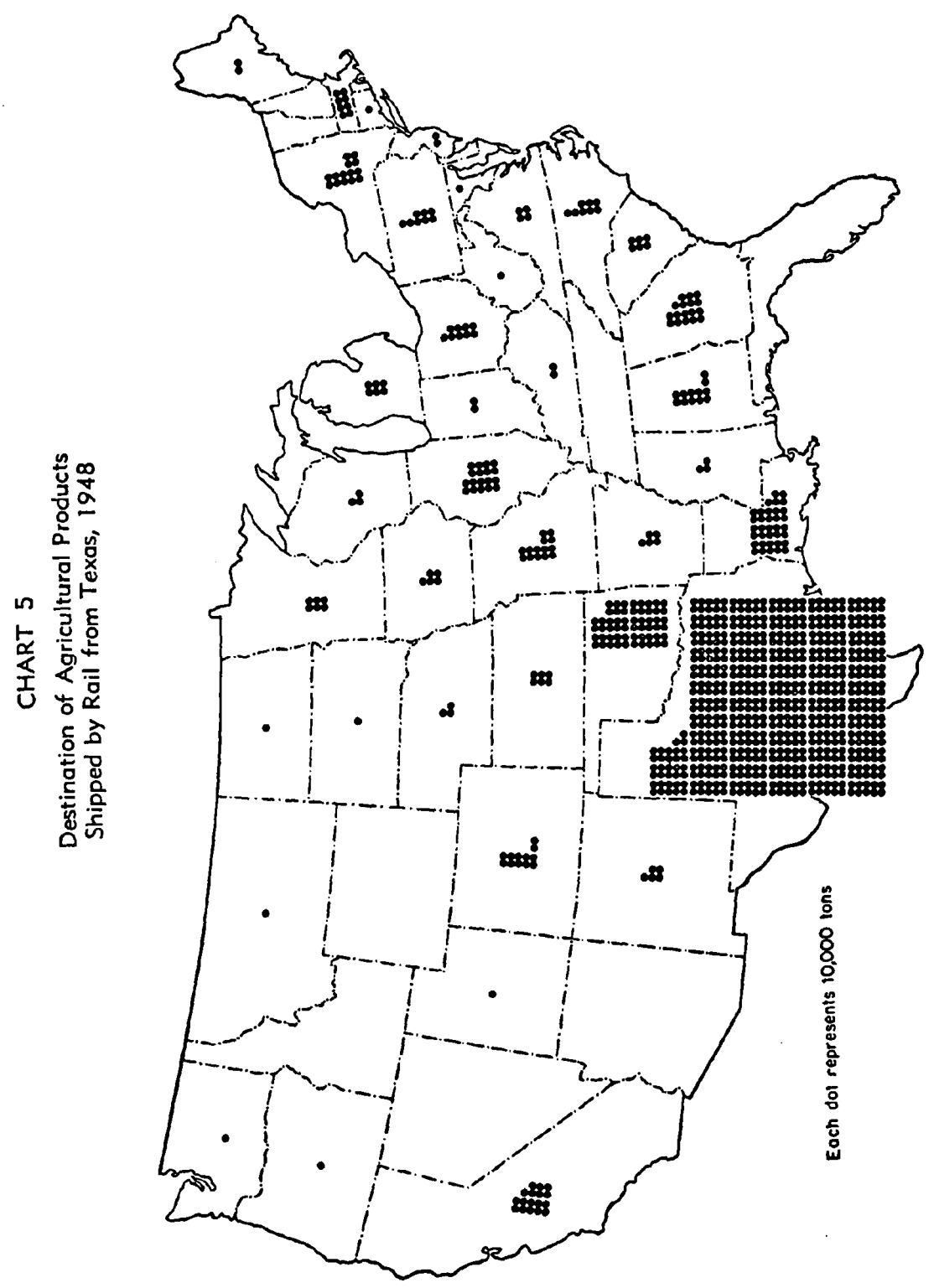


REGIONAL AND NATIONAL PRODUCT

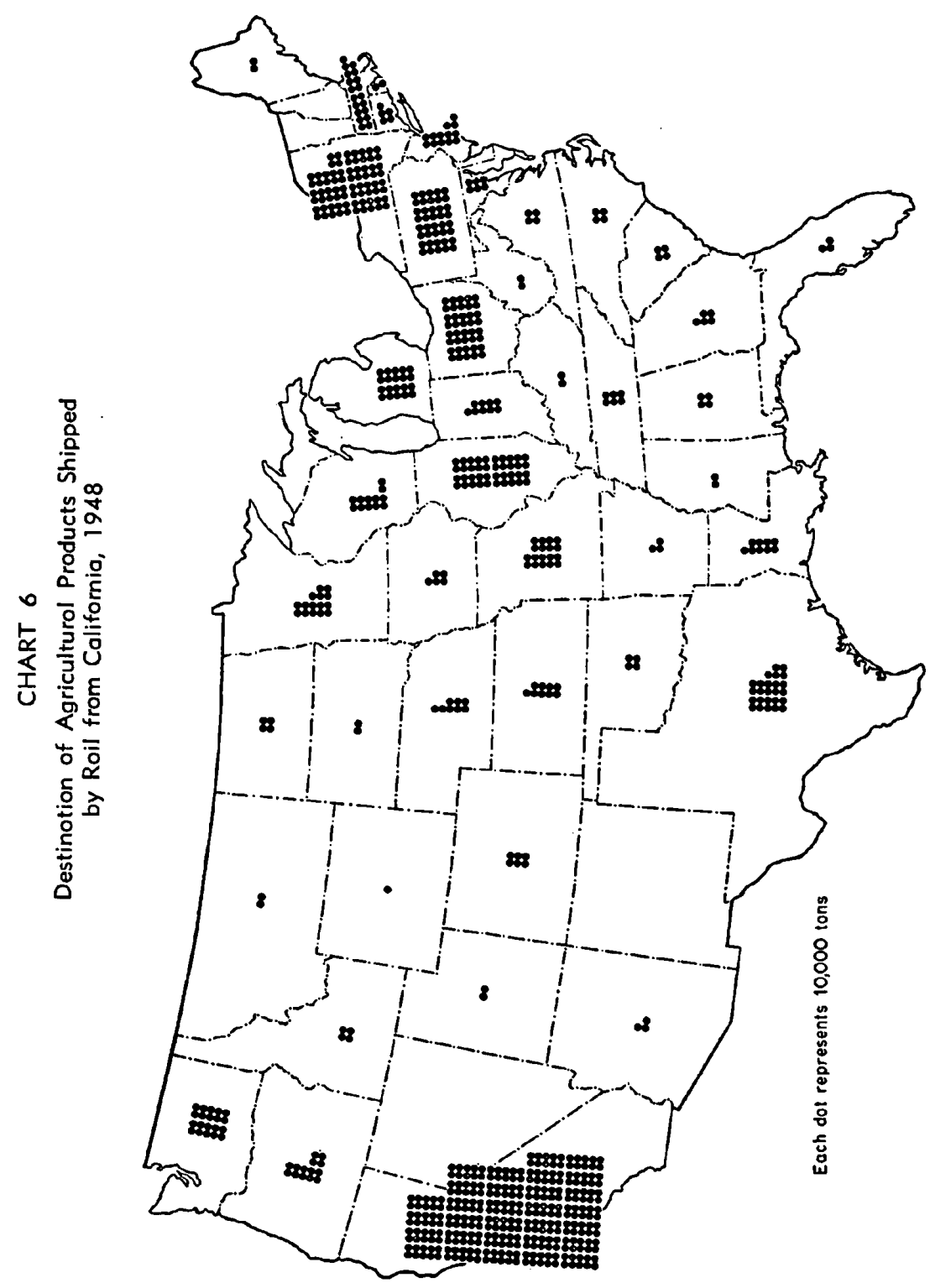




\section{REGIONAL AND NATIONAL PRODUCT}

istics of particular types of commodities, such contrasts have more analytic value.

The ICC classifies commodities into five broad groups: products of mines, agricultural products, animal products, forest products, and manufactured products. Comparison of these groups yields contrasts in transport characteristics that illuminate the differences of commodity flows among the states. Charts 3 and 4 represent the destination of products of mines and manufactured products originating in Iowa. The shipments of products of mines terminate for the most part within the state, and fall off very rapidly with distance. This is a characteristic of mine product shipments of all states and is a reflection of the high weight, low value (per ton), and ubiquitous nature of many products of mines. In contrast, the flows of manufactures from Iowa fall off less sharply with distance. Were the data in dollar value, the contrast would persist.

On the basis of such contrasts for each of the five groups of commodities, it is tempting to generalize on the nature of a state's (or a region's) interrelations with other states (regions). Such generalization might imply that the greater the proportion of a state's total production represented by mining, the fewer the states with which it would be interrelated. However, such generalization can easily be misleading. For example, examination of Ullman's charts reveals a general west-to-east movement of commodities. For most states, sources of products of mines, agricultural products, forest products, and animal products are chiefly to the west. The destination of these products plus the sources of manufactured products are for most states toward the east and north. This general movement of commodities toward the peak of population and income potential partially explains the differences in the flows out of Connecticut and those out of Washington. Connecticut is a producer of manufactured goods primarily-goods which characteristically give rise to longer flows than any other group. However, because Connecticut is so close to the center of the national market, shipments originating in that state flow relatively short distances.

In addition to unequal market potentials, differences in the "transportability" of individual commodities and inequalities of resource endowment preclude generalization on the basis of such broad groups of commodities. Within these groups, there are quite likely to be commodities with transport characteristics so 
different that the same group when examined for different states or regions shows different flow characteristics. For example, we have selected from Ullman's charts those depicting agricultural product flows out of Texas and California. (See Charts 5 and 6. $)^{19}$

Texas represents the typical pattern of agricultural commodity flows. These flows are usually concentrated within short distances; relatively few cover long distances. In contrast are the much larger national flows of California agricultural products. They are a reflection of California's unique resources for fruit and vegetable production. The nature of Washington's "all commodity" flows can likewise be understood only in the light of its particular resource structure, its distance relations with other regions, and their particular resource structure.

In short, aggregative flow data are helpful in understanding the magnitudes of the major interstate or interregional relationships. But for purposes of analysis, it is essential to study individual commodity flows.

The mutual impact of change in the various regions is channeled through individual commodity flows; hence the most rigorous type of regional projection ought to project each flow. For the present this is not generally a practicable procedure. However, in those instances where a few flows-steel, fuel, etc.may dominate a region's external relations, there would be great pragmatic value in a general technique for analyzing flows. Such a technique could shed additional light on the problems involved in making projections from econometric, input-output, and other models. For example, the $\beta_{i}$ of the simple model presented above will change as the flows change. If an industry (particularly a major industry) shifts from region $i$ to region $j$, this will be manifest through a change in flows. There will be a change in $\beta_{i}$ as the links between the regions change. In addition, there will be the many secondary effects as market and supply area relationships for all the dependent industries are realigned.

An approach in terms of general substitution analysis yields a basis for the explanation and projection of changes in flows. Some of the substitution resulting in alteration of flows can be expressed in standard terms. For example, consider the historical

\footnotetext{
${ }^{10}$ Since the charts represent tonnage movements and since magnitudes differ in the two states, the reader should be careful to interpret these in a relative sense.
} 
shift of textile plants out of New England, when technological development opened employment to unskilled labor. The movement to the South to take advantage of a cheap labor supply involved, among other substitutions, the dominant one of southern unskilled labor (a relatively immobile resource) for skilled New England labor (another geographically conditioned resource).

However, the inclusion of the space factor requires that attention be given to two new basic types of substitutions: ${ }^{20}$

Substitution between transport outlays and other outlays, whether on one or more factors. Two examples are: (a) In glass manufacture, the substitution of natural gas for coal resulted in a shift of the industry to sources of natural gas. Historically, when the direction of the shift was away from the established markets, this amounted to a substitution of transportation outlays for fuel outlays. (b) The problem of the economic justification for an integrated steel mill in New England may be viewed, for the most part, in terms of substitution between transport outlays and all other outlays combined. The mill becomes feasible when the previously high potential outlays on production have fallen suffciently (due to a growing market, which reduces the diseconomies of scale associated with a limited market) to allow substitution of production outlays for transport outlays involved in satisfying New England steel demand. ${ }^{21}$

There are many other industrial activities which begin development in a region when the increasing regional market has reduced the diseconomies of scale to the point where production outlays can be substituted for transport outlays. Cement production and automobile assembly are two such activities.

Substitution among distance inputs..$^{22}$ Analysis in terms of this type of substitution would, for example, help to predict the construction of a Trenton steel mill following the discovery of foreign ore sources. Essentially, the steel industry is transport-oriented, the variation among sites of costs other than transport being

${ }^{20}$ For full elaboration of these types, refer to W. Isard, "Distance Inputs and the Space-Economy," Quarterly Journal of Economics, Vol. Lxv, May and August 1951.

21 The reader should bear in mind that in serving the New England market, the transport outlays for a New England mill would be lower than those for a Pittsburgh mill, whereas production outlays would continue to be higher for the former.

22 A distance input is defined as the movement of a unit of weight over a unit of distance. See Isard, "Distance Inputs and the Space-Economy," op.cit., for full conceptual treatment. 
minor for a market of sufficient size. In terms of the New YorkPhiladelphia market, the Trenton development involves the substitution of distance inputs in the movement of coal and ore for distance inputs in the movement of finished product and scrap.

Thus, whatever the terms of substitution analysis, ${ }^{23}$ it does allow prediction of shifts in location of major industrial categories and, as a consequence, the prediction of realignments of flows. For projecting regional development, substitution analysis is a useful supplement to econometric, input-output, and other techniques. And, as in the case of the Pacific Northwest, substitution analysis for a few dominant flows may be a valid technique in itself.

\section{E. REGIONAL PROJECTIONS IN BROAD INDUSTRIAL AGGREGATES}

The preceding analysis, developed in terms of flow phenomena, can lead to a model which is, in general, nonoperational (except in a few cases), though substitution analysis seems the most desirable from a theoretical standpoint. On the other hand, the set of equations 18 of Section C, while statistically operational, paid no attention to the industrial structure of the several regions (other than through the derived $\beta$ coefficients). In this section, we shall examine the possibility of an alternative aggregative approach to regional projections, but one which involves less aggregation than the model represented by the set of equations 18 . This permits us to give weight to industrial composition without being forced into nonoperational analysis.

Colin Clark's conceptual classification of all forms of economic activity into primary, secondary, and tertiary has proven extremely useful in regional studies, especially for isolated regional analysis, and for historical comparison of development in different regional economies. However, for purposes of interregional analysis, it conventionally ignores the space element and the influence of distance in shaping flows.

We now inquire how to adapt this framework to regional analysis and projections of regional product (given a national projection). As before, we start with the identity

$$
{ }_{i} \mathrm{GRP}_{t}={ }_{i} L_{t} \cdot{ }_{i} \Gamma_{t}
$$

${ }^{28}$ Location studies are essentially comparative cost studies, and these reduce to substitution analysis. 


\section{REGIONAL AND NATIONAL PRODUCT}

which can be broken down into the identity

$$
\begin{gathered}
{ }_{i} \mathrm{GRP}_{t}={ }_{i} L_{1_{t}} \cdot{ }_{i} \Gamma_{1_{t}}+{ }_{i} L_{2 t} \cdot{ }_{i} \Gamma_{2_{t}}+{ }_{i} L_{3_{t}} \cdot{ }_{i} \Gamma_{3_{t}} \\
(i=1,2, \ldots, m)
\end{gathered}
$$

where ${ }_{i} L_{1_{t}},{ }_{i} L_{2_{t}}$, and ${ }_{i} L_{3_{t}}$ represent annual employment in year $t$ in primary, secondary, and tertiary industries, respectively, in region $i ;{ }^{24}$ and where ${ }_{i} \Gamma_{1_{t}},{ }_{i} \Gamma_{2_{t}}$, and ${ }_{i} \Gamma_{3_{t}}$ represent average productivity in year $t$ in primary, secondary, and tertiary activities, respectively, in the region.

For purposes of projection, it might be assumed in a first model that the existing proportions $L_{1} /{ }_{i} L,{ }_{i} L_{2} /{ }_{i} L,{ }_{i} L_{3} /{ }_{i} L$ remain constant. To obtain GRP one year hence, we might multiply current gross product from each of the three categories by (1) unity plus the rate of increase in ${ }_{i} L$ (total annual regional employment) and (2) unity plus the appropriate rate of increase in productivity derived by historical trends. The trends in each case are regional trends. This procedure, however, has obvious shortcomings.

In a second model, we might allow for a historical shift in the proportion of total employment accounted for by ${ }_{i} L_{1},{ }_{i} L_{2}$, and ${ }_{i} L_{3}$. For the first approximation, we take the given national projection and the shifts in the national categories, $L_{1}, L_{2}$, and $L_{3}$, implied there and assume that the same relative shifts apply for the region. Thus, let $r_{1}$ be the annual rate of shift into $L_{1}$ derived from a trend projection and relevant for year $t_{1}$; and let $r_{2}$ be the annual rate of shift into $L_{2}$ derived from a trend projection and relevant for year $t_{1}$. Both $r_{1}$ and $r_{2}$ can take either a positive or a negative sign depending upon the direction of the shift. A rate $r_{3}$ is not necessary since the shift within $L$ to or away from tertiary industries is determined once $r_{1}, r_{2}$, and $L$ are given. Our projection equations become:

$$
\begin{gathered}
{ }_{i} \mathrm{GRP}_{t_{1}}={ }_{i} L_{1_{t_{1}}}\left(1+r_{1}\right)\left(1+z_{1}\right) \Gamma_{1_{t_{0}}}+ \\
{ }_{i} L_{2_{t_{1}}}\left(1+r_{2}\right)\left(1+z_{2}\right) \Gamma_{2_{t_{0}}}+\left({ }_{i} L_{3_{t_{1}}}-r_{1} \cdot{ }_{i} L_{1_{t_{1}}}\right. \\
\left.-r_{2} \cdot{ }_{i} L_{2_{t_{1}}}\right)\left(1+z_{3}\right) \Gamma_{3_{t_{0}}} \\
(i=1,2, \ldots, m)
\end{gathered}
$$

where

$$
\begin{aligned}
& { }_{i} L_{\mathbf{1}_{\mathbf{t}_{\mathbf{1}}}}={ }_{i_{i}} L_{\mathbf{1}_{\mathbf{t}_{0}}}(1+p) \\
& { }_{i} L_{2_{t_{1}}}={ }_{i} L_{2_{t_{0}}}(1+p)
\end{aligned}
$$

24 Any system of classifying industries into a few relatively homogeneous groups would be satisfactory. 
and

$$
{ }_{i} L_{3_{t_{1}}}={ }_{i} L_{3_{t_{0}}}(1+p)
$$

As before, $p$ is the projected national rate of population increase for the year $t_{1}{ }^{25}$ and $z_{1}, z_{2}$, and $z_{3}$ are nationally projected rates of change in average productivity in primary, secondary, and tertiary activities, respectively. $\Gamma_{1_{t_{0}}}, \Gamma_{2_{t_{0}}}$, and $\Gamma_{\mathbf{s}_{t_{0}}}$ are average regional productivities for the year $t_{0}$ in primary, secondary, and tertiary activities, respectively.

In order to account for regional rather than national rates of change in productivity, $s_{1}, s_{2}$, and $s_{3}$ may be substituted for $z_{1}, z_{2}$, and $z_{3}$ in equation 21 . The former rates refer to change in $\Gamma_{1}, \Gamma_{2}$, and $\Gamma_{3}$, respectively, and relate to region $i$ alone. They can be determined from historical trend extrapolation, or from more specific knowledge about changes in industrial productivities, and changes in the relative importance of the components of a particular industrial classification for the region.

Equation 21 can be further revised by substituting regional rates of employment shifts $\left({ }_{i} r_{1}\right.$ and $\left.{ }_{i} r_{2}\right)$ for the national rates $\left(r_{1}\right.$ and $\left.r_{2}\right)$. Historical information on regional employment shifts ought to be obtainable in certain cases. When not available, it is still possible to predict, to a limited degree, shifts among primary, secondary, and tertiary activities for a region.

Thus far, interrelations among regions have been omitted. A convenient way of introducing these and other considerations of distance is to use a cross classification, local and interregional. We denote activities as primary local, primary interregional, secondary local, secondary interregional, tertiary local, and tertiary interregional. The classification "local" in each case implies no flows outside the region. Thus, by definition, regional interrelations are manifest only through primary, secondary, and tertiary interregional activities. The influence of the distance factor can enter through reintroduction of the concept of income potential to yield equation 25. Each equation in this set has two main parts. The first reflects intraregional development; the second, interregional.

${ }^{25}$ Use of a national rate of population growth prevents us from directly taking account of differences in fertility among regions, interregional migration, etc. To some extent, however, these other factors which influence regional rates of population growth are reflected indirectly in shifts among types of activity and, later, in different regional productivity rates. 
REGIONAL AND NATIONAL PRODUCT

$$
\begin{aligned}
& { }_{i} \mathrm{GRP}_{t_{1}}={ }_{i} L_{1_{t_{1}}}\left(1+r_{1}\right)\left(1+s_{1}\right) \Gamma_{1_{t_{0}}}+{ }_{n i} L_{2_{t_{1}}}\left(1+r_{2}\right) \\
& \left(1+s_{2}\right) \Gamma_{2_{t_{0}}}+\left({ }_{k} L_{3_{t_{1}}}-r_{1} \cdot{ }_{m} L_{1_{t_{1}}}-r_{2} \cdot{ }_{{ }_{i}} L_{2_{t_{1}}}\right) \\
& \left(1+s_{s}\right) \Gamma_{s_{t_{0}}}+{ }_{g i} L_{\mathbf{1}_{t_{1}}}\left(1+\delta_{1}\right)\left(1+s_{1}\right) \Gamma_{\mathbf{1}_{t_{0}}} \\
& +{ }_{i t} L_{2_{t_{1}}}\left(1+\delta_{2}\right)\left(1+s_{2}\right) \Gamma_{2_{t_{0}}}+{ }_{g_{i}} L_{3_{t_{1}}}\left(1+\delta_{3}\right) \\
& \left(1+s_{3}\right) \Gamma_{3_{t_{0}}}
\end{aligned}
$$

where the subscripts $h$ and $g$ denote local and interregional activity, respectively. In equation 25 ,

$$
\delta_{1}=\frac{b_{1}\left(\frac{{ }_{i} V_{t_{1}}}{{ }_{b} V_{t_{0}}}-1\right)}{{ }_{j l} L_{1}}
$$

where $b_{1}$ may be taken as the slope of a simple line of regression measuring the historical relationship between changes in primary interregional employment and $\left[\left({ }_{i} V_{t_{1}} /{ }_{i} V_{t_{0}}\right)-1\right] .^{28} \delta_{2}$ and $\delta_{3}$ are defined similarly, except for subscripts. In this formulation, $r_{1}$ and $r_{2}$ can be taken as either national or regional shift rates among local activities only, preferably regional. The term ${ }_{o_{i}} L_{\mathbf{1}_{t_{1}}}$ $\left(1+\delta_{1}\right)\left(1+s_{1}\right) \Gamma_{1_{t_{0}}}$ stands for "gross product of primary interregional industries in region $i$." Explicitly, the term stands for: (1) the employment in primary interregional activities in region $i$ in time 1, plus or minus the shift in employment as a result of relative changes in the income potential of the region, multiplied by (2) the average productivity in primary activities.

The model, thus far, relies simply on historical observations. Primarily, rates of growth and shifts are determined, and these are modified in ways additional knowledge may suggest. The introduction of income potentials necessarily entails simultaneous determination of GRP for each region. The GRP's are the only unknowns. (An $n$-region economy will have $n$ equations in the set.) The summation of GRP's obtained through solution of equation 25 may yield a GNP

$$
\left(\mathrm{GNP}=\sum_{i=1}^{i=m} \mathrm{GRP}\right)
$$

considerably different from that which a simple one-point model may yield. As previously, it may be desirable here to introduce a

${ }^{20}$ Since ${ }_{0_{1}} L_{1_{1}}$ is given in terms of population, $\delta_{1}$ must be expressed as a pure number. Hence, the term in the numerator of equation 26, which expresses an increment in terms of population, should be divided through by orth. 


\section{REGIONAL AND NATIONAL PRODUCT}

$\beta$ factor to modify the interregional effects traceable through income potential. This may be required in the light of detailed information from study of flow analysis and projected substitutions involving location shifts and changes in resource utilization. Also, it may be required for purposes of consistency.

The foregoing model encompasses the distance factor in two ways: (1) It recognizes that markets and the spatial extent of economic activities vary. Production and consumption of different commodities balance within areas of varying size. Thus the amount of activity classified as local within a region will depend upon the selection of regional boundaries. In general, the smaller the area the more important it is to consider external relations. (2) It recognizes that, in general, these external relations will be affected by changes in income in all other regions inversely as the distances of these regions from the given region.

As in equations 19, changes in GRP in region $i$ might be linked directly to changes in GRP in every other region by means of $\beta$ coefficients and separate incremental income-distance relations. This would avoid the undesirable aggregation of linkages in a single measure of income potential. However, as with equations 19 , the model becomes nonoperational with such modification. Elaborate and questionable statistical techniques are required to eke out a set of $\beta$ 's from the limited data.

We can push the analysis still further by setting forth the industrial structure of region $i$ in greater detail and by relating each industry in region $i$ to industries in other regions via interregional flows. Such a procedure appears nonoperational except where, as mentioned above, a few major flows dominate the interregional trade of an area. However, with suitable modifications and restrictions, it leads toward an operational input-output model.

Before developing regional input-output analysis, we should try to ascertain to what extent certain manifestations of differential regional rates of growth appear explicitly in equation 25, and to what extent they appear only implicitly, if at all. Among the most readily apparent ones are those associated with population increase, interregional population migration, and rural-tourban population shifts. Consider, first, population increase and migration, for these are not independent.

In our model, a change in ${ }_{n i} L_{1},{ }_{i} L_{2}$, and ${ }_{n i} L_{3}$ (employment in local activities) is associated with an average national rate of 
population increase. On the other hand, the $\delta_{1}, \delta_{2}$, and $\delta_{3}$ which relate ${ }_{g i} L_{1},{ }_{g i} L_{2}$, and ${ }_{g i} L_{3}$ (employment in interregional activities) to income potential are regionally differentiated. This means differential rates of change in total employment opportunities in the several regions. If net reproduction in each region exceeds (or is less than) the increase in that region's employment opportunities, we can partially account for emigration (or immigration). Thus, also, we indirectly arrive at over-all regional population projections. ${ }^{27}$

Existing factor immobilities, occupational as well as geographic, are also reflected in the model, especially if no marked changes in immobilities take place. Immobilities dull the response to changes in new employment opportunities and are thus reflected in the historical data from which $r_{1}, r_{2}, \delta_{1}, \delta_{2}$, and $\delta_{3}$ have been derived.

It is clear that employment in local industries should be differently affected in each region, if employment in interregional activities experiences different rates of change. To some extent, this can be recorded in the model through use of regional rates of shift, $r_{1}$ and ${ }_{i} r_{2}$. These rates are based on regional experience and can (for any given year) be viewed as reflecting, in part, previous differential rates of change among regions in the growth of interregional activities.

Closely associated with population growth and migration are changes in spatial population patterns, in particular the rural-tourban shift. This shift differs in intensity from region to region, and though it does not enter explicitly into the model, it is partially reflected in changes in ${ }_{i} r_{1}$ and ${ }_{i} r_{2}$ (the rates of shift out of primary and secondary industries).

Consumption patterns also differ from region to region owing partly to differences in income and degree of urbanization, and partly to differences in tastes (though the importance of this latter factor in an era of rapid transportation and mass communication media is uncertain). On the one hand, these differences in consumption patterns are of importance in determining which commodities flow into the region from others and thus affect the pattern of interregional primary, secondary, and tertiary

${ }^{27}$ Note that this technique for deriving regional population projections does not imply that differential rates of population growth among regions will be gradually eliminated. This is assumed, for example, in M. J. Hagood, Prospects for Regional Distribution of the Population of the United States (Bureau of Agricultural Economics, November 1949). 
activities in other regions. On the other hand, they markedly condition intraregional response to changes in income. Thus, in an agricultural region like the South, the rate of shift out of primary production has tended to be more intense than in an industrial area. These contrasting effects are traceable in our model through the different values of the ${ }_{i} r$ 's which would be determined from historical data.

One of the significant factors excluded, even implicitly, is the possibility of major, abrupt geographic shifts of industry and changes in resource use caused by technological progress. To some extent, these can be allowed for by the exercise of judgment. The direct influence upon a region of the construction and maintenance of a major atomic energy installation can be roughly gauged. Likewise, the direct influence of continuous casting of steel can be estimated, if this revolutionary process should prove feasible for a large fraction of steel production. In contrast, the model does allow for gradually changing resource use and shifts of location. For example, the gradual shift of industry and population to California is in part explained by the gradual decrease in material orientation, particularly coal and ore orientation. This decrease implies a relative increase in the strength of California's climatic attraction. The $\beta, r$, and $s$ coefficients of the model should reflect this and similar developments.

\section{F. THE REGION AS AN ANALYTIC CONCEPT}

Thus far we have discussed regional analysis without indicating the implications involved in the use of the concept of a region. As mentioned earlier, a complete analytic description of economic reality would distinguish each component by location, as well as by function or other criteria. Just as the term "industry" is used to sum components sharing similar characteristics, so apparently is the term "region" used to sum components contiguous in space. The empirical content of the "industry" will vary as the criteria selected to distinguish industries. The same holds true for the content of the "region." There appears to be no unique-definition of an industry; the criteria for industrial aggregation depend upon the purposes for which the concept is used. Even a cursory examination of the great variety of definitions of a region suggest that it, too, has no unique meaning.

When a group of activities are spatially aggregated into a 
region, there are implied certain observable "facts" concerning the internal structure of the region, as well as its external relations, those with other regions. It is implied that each region can be distinguished from other regions according to some workable criteria. The regional boundaries are not randomly drawn. Further, the criteria for regional demarcation should be derived from the framework of analysis to be used. Regional definition or sets of boundaries in use by other disciplines and for other purposes cannot be taken as valid for the economist's use without an examination of their economic meaning. For the economist, a definition is in general derivable only to the extent that his analysis can reveal the role of distance in the functioning of the economic system. Thus, an inquiry into the meaning of a region for economic analysis might begin with an inquiry into the role of space in shaping the economy. This is not the place for an extensive development of such an inquiry, but certain considerations are relevant.

The existence of a spatial dimension in an economic system imposes limitations on economic interaction. Transforming scarce resources into goods and services ${ }^{28}$ requires the use of other scarce resources for transport when different phases of the transformation process are separated by distance. At any one point in time, given the existing distribution of resources and the existing techniques of transportation and communication, specialization and division of labor take place with regard not only to function, but to location as well. The relations between phases of the transformation process, and hence their economic interdependence, are reflected through flows of commodities from point to point. Since space acts as a barrier to economic intercourse, primarily through transport costs, the magnitude of these flows will be attenuated by distance. If these flows are regarded as bonds which link components of the system to one another, it can be seen that the greater the magnitude of the flows in any area, the more highly interrelated are the components in that area. Further, if there is a tendency for economic activity to agglomerate around certain focal points, an examination of flows over a wide geographic area will reveal this. As the distance from a focal point become's greater, the magnitudes of the flows will diminish, some more rapidly than others. Conversely, as a focal point is ap-

28 Transformation includes transportation of each unit of output to the point of final consumption. 


\section{REGIONAL AND NATIONAL PRODUCT}

proached, the flows will increase in magnitude. If around such a focal point, a boundary be struck as a locus of points where flows fall to a minimum, it could be said of the components within the boundary that they exhibit a relative maximum (and generally a high degree) of interdependence. (The total magnitude of all the flows within the area is necessarily greater than those linking the area to others.) Such demarcation could be said to embrace a "natural" aggregation over space of economic activities, an aggregation due, in large part, to the impact of distance. Regions of this type might be the regions we seek. Our criterion for regional demarcation would then be internal interdependence of income, as revealed through flow phenomena. Furthermore, if there are such natural aggregations, and if the aggregations display a hierarchical tendency, then we might expect to find regions of varying order.

The preceding remarks serve to focus attention on the necessity of studying flow phenomena in general. Certain considerations help us to systematize the study of these flows in such a way as to shed light more directly on the problem of regional demarcation.

$\mathrm{Lösch}^{29}$ has developed theoretical grounds for anticipating that economic activities will cluster around foci. Under assumptions of equal distribution of resources, population, technical knowledge, etc., the market area for the product of any producer tends toward a hexagonal shape. The size of this area will be determined by the transport characteristics of the product, on the one hand, and economies of scale, on the other. Ceteris paribus, the lower the cost of transporting a unit, the greater the market area; and the greater the economies of scale, the greater the market area. Consequently, goods with different characteristics in these respects will have different market areas. Lösch's system can be envisaged as a plane overlaid with systems of nets of market areas, each net corresponding to a particular product. To minimize transport costs in each plane, these systems should be ordered around a common central point (a first-order center). From this point all commodity flows are outward (given Lösch's highly unrealistic assumptions). Cutting these flows at successively in-

${ }^{29}$ A. Lösch, Die räumliche Ordnung der Wirtschaft (2nd edn.; Jena: G. Fisher, 1944). See also N. S. B. Gras, An Introduction to Economic History (Harper, 1922); A. Hawley, Human Ecology: A Theory of Community Structure (Ronald, 1950); R. D. McKenzie, The Metropolitan Community (McGraw-Hill, 1933). 


\section{REGIONAL AND NATIONAL PRODUCT}

creasing distances from this center reveals irregularly diminishing outward flows as the limits of successively increasing market areas are passed. At the same time, flows in the reverse direction progressively increase in magnitude, though irregularly, as the distance to the closest center of a second order diminishes.

In empirical terms, Lösch's scheme implies that major cities service a large hinterland and that the service function of the major city reduces to fewer and fewer services as the distance from the city increases. Bonds with the major city are attenuated by distance. It further implies an organic relationship between a major city and its hinterland (interdependence of incomes). Bogue has given strong support to this observation in his study of metropolitan dominance. "The metropolitan community appears to be an organization of many mutually interdependent and inter-functioning subcommunities oriented about the hinterland cities which in turn are subdominant to and interdependent with the dominant metropolis, and inter-function with it." ${ }^{30}$ Bogue's investigation reveals that the hinterland cities specialize in some functions at a level above that of the small towns, and the metropolitan center at a level above that of the hinterland cities, with no one center dominating all activities.

In terms of flows, this means that the great bulk of flows will traverse relatively short distances; that longer flows will connect foci; and that the greater the distance separating these foci, the smaller the magnitude of the flows and the fewer goods and services represented. Further, this means that intercepting flows equidistant from and on either side of a subdominant center will not yield flows of the same magnitude. The magnitude of flows will be at a relative minimum when the boundary is drawn between two foci oriented toward different foci of a lower order.

If we now recognize that goods and services have market areas of varying size which can be ranked from largest to smallest, we may have a basis for demarcating regions of any order. ${ }^{31}$

${ }^{30}$ D. J. Bogue, The Structure of the Metropolitan Community (University of Michigan, 1949), p. 59.

${ }^{31}$ In geographic terminology such regions are "nodal" regions. "They are units possessing an internal structure, comprising a focus (or foci) and surrounding areas tied to the focus. They are bounded by the disappearance or the differential weakening of the tie in favor of a tie to some other focus." Committee on Regional Geography, "Regional Geography," 4th revised outline, February 1950, American Geography: Inventory and Forecast. Note also that such criteria eliminate the confusion between the so-called heterogeneous and homogeneous regions. In terms of flows, both "types" of regions 


\section{REGIONAL AND NATIONAL PRODUCT}

Regions of the $i$ th order can be said to be those in which there is balance between production and consumption of goods of the $i$ th order (corresponding to the $i$ th net of market areas), and relatively little imbalance of higher-order goods, which are those having smaller market areas.

However, Lösch's model and Bogue's averaging techniques fail to catch major flows attributable to inequalities in resource endowment. These flows greatly complicate the orderly Lösch model..$^{32}$ However, they may very well be the major substance of interregional relations. This is particularly the case when few, but large, regions (low-order regions) are the subject of analysis. There are relatively few goods of a central function which cross such regional boundaries, these being the goods of first order. Here the flows of resource-oriented goods, where resources are localized, tend to dominate the picture, and to a different extent for the several regions. ${ }^{33}$

reduce to the same thing. An area which is heavily specialized in production will have heterogeneous inflows and relatively few outflows. For a region with more diversified production, there may or may not be diversified inflows. Each type will be clearly distinguishable as a region with reference to these criteria, whereas identification in terms of the nature of production obscures the essential role played by space in regional differentiation.

32 This was observed and stressed by $A$. Lösch in his empirical work "The Nature of Economic Regions," Southern Economic Journal, July 1938; and in part $\amalg$ of his Die räumliche Ordnung der Wirtschaft, as cited.

${ }^{33}$ In recent years geographers have shown. an intense interest in the development of the regional concept. The Committee on Regional Geography has set forth an outline of its views in some detail. The essence of its approach is the view that the term "region" is an analytic tool, a conceptual device having great value when related explicitly to a particular frame of reference. Thus the concrete determination of any set of regional boundaries will vary among disciplines, but the meaning of the concept should be common to all. In this respect, it is interesting to paraphrase portions of the outline on "Regional Geography," op.cit., to illustrate the relevance of this point of view: Areal differentiation, because of difference from place to place, is necessary in some cases and convenient in most. While permitting the recognition of causes, it does not impose a genetic presentation. It groups data into homogeneous segments of any size whatever, homogeneity being confined to the criteria whereby the units are differentiated. The units thus set apart are regions, each with an internal integrity, defined by its criteria. The region is fixed in a hierarchy of subdivisions. Commonly there is a core area, beyond which lies a marginal area. Distance alone tends to weaken the ties to the focus as the perimeter of the region is approached. All regions are impermanent and, in that sense, fluid. This change may be confined to internal rearrangements of a major region leaving the over-all pattern of regions unaltered: or it may require the reconstitution of one or more areal units. Such change is most likely to affect the boundaries 


\section{REGIONAL AND NATIONAL PRODUCT}

\section{G. REGIONAL INPUT-OUTPUT ANALYSIS}

In the preceding sections, we have discussed techniques for deriving projections of gross regional product using very broad aggregates. In this section, we shall examine the possibility of adapting input-output techniques to regional and interregional analysis as a means of tracing out, in greater detail, industrial interrelations which lie behind regional change.

Input-output analysis, as developed by Professor Leontief, is essentially a Walrasian system of general equilibrium made operational through suitable modifications. ${ }^{34}$ As such, it focuses attention on interindustry relations in a spaceless economy. These relations are reflected in structural coefficients, which are derived from technical production functions and household income-consumption patterns. The industrial aggregates are composed of units with similar input-output structures. Given such a system, it is possible (within the limits set by the assumptions) to describe the differential industrial impact of hypothetical changes in the bill of goods. Implicit in such a description is the assumption that differences in location of the units of any aggregate do not have any effect upon the system. However, in fact they do, and the effect of these differences should be considered.

In general, two types of approach are conceivable. The first we shall designate as the "balanced regional" model, and the second, as the "interregional" model. Both can be viewed as at-

of regions, since, in any case, these are the most troublesome, being both transitional and critical.

The paraphrase could be extended at length, but the foregoing is enough to show that the conceptual content of the term "region" can be made identical among disciplines without implying any similarities in the empirical content of the term. Our concept of a region is completely compatible with that of the geographer, but our selection of criteria for the demarcation of actual regions may be entirely different from that of the political scientist, the sociologist, etc. In this connection, it is pertinent to suggest that use of existing regional classifications in economic analysis be examined critically for consistency between the criteria that were used to set up the classification and criteria of use to the analyst.

${ }^{34}$ There is a growing body of literature concerned with input-output analysis. The reader unfamiliar with the techniques and the terminology should refer to W. W. Leontief, The Structure of the American Economy, 1919-1929 (Harvard University Press, 1941), and the following articles by Professor Leontief: "Output, Employment, Consumption, and Investment," Quarterly Journal of Economics, Vol. LviI, February 1944; "Exports, Imports, Domestic Output, and Employment," Quarterly Journal of Economics, Vol. Lx, February 1946; "Wages, Profit, and Prices," Quarterly Journal of Economics, Vol. IxI, November 1946. 
tempts to describe the differential industrial and regional impact of a hypothetical change in the bill of goods.

\section{The balanced regional model}

Professor Leontief recently developed a balanced regional model which ties in with our previous discussion of flows. ${ }^{35}$ It was pointed out that regions of varying order according to the type of commodity flows crossing regional boundaries could be conceived of. Thus, in the case of a region of order $m$ there will be $1,2,3, \ldots, m-1$ classes of goods flowing across the boundary and a relatively high degree of balance between production and consumption within the region for the remaining $n-m$ goods. For simplicity, the following discussion will consider only one order of regions and classify all goods as either "national" or "local." National goods are those which flow across regional boundaries; local goods are those which balance within the region. However, the analysis can be generalized to cover all orders of regions.

The data for the balanced regional model consist of all the elements usually present in input-output studies. In addition, Leontief's model assumes that the spatial production pattern of all national commodities is known and constant. This constancy of the geographic production pattern is inserted as a useful approximation in lieu of more detailed information. For short-run analysis, it implies that the regional share of total output of a specified national commodity remains the same at all levels of output of that commodity. For longer-run analysis, it implies no locational shifts. This approximation is represented by a set of constants showing the share of each region in the total output of every national commodity.

A second modification of the conventional input-output model concerns the bill of goods. Not only must there be specified a bill of goods for the nation, but also a bill of goods for each region in terms of local goods only.

Further, household demand is not entered into the bill of goods as in the usual procedure. Rather, households are included in the set of structural equations as a local industry. This is desirable in order to retain the local income multiplier effect and to show the impact of derived changes in intraregional employment upon the output of local industries. This is obviously an important

${ }^{35}$ Studies in the Structure of the American Economy (Oxford University Press, 1953), part II. 
source of differential reaction among regions having different industrial structures.

Thus, given the additional information on the geographic production pattern of all national goods and the local bill of goods for each region, the demand for products of local industries of each region can be determined.

The general outlines of Professor Leontief's model are as follows: The outputs of all national commodities are found by multiplying the national bill of goods by the inverse of the matrix of input coefficients. This is straight input-output procedure. Symbolically, this is given by ${ }_{N} A^{-1} Y$, where $Y$ is the national bill of goods, $A^{-1}$ is the inverse of the matrix of input coefficients, and ${ }_{N} A^{-1}$ is a section of the inverted matrix which when multiplied by the bill of goods yields required national outputs of national industries.

With knowledge of the outputs of all national industries, the next step is to allocate these outputs geographically. This is done by multiplying each of these outputs by the previously determined set of constants-in this case, simple proportionality factors. Thus, ${ }_{j} R_{N} A^{-1} Y$ represents the output of national goods required of region $j$, where the diagonal matrix ${ }_{j} R$ consists of a set of constants which state the portion of the output of each national commodity produced in region $j$.

Among the various inputs required in each region to produce the national goods will be those which are of a local character, e.g., local transportation, utilities, construction, etc. We can let the matrix $A_{L . N}$ represent the set of input coefficients which state the requirements of local commodities per unit of output of national commodities. Multiplying ${ }_{j} R_{N} A^{-1} \boldsymbol{Y}$ by $A_{L N}$ we have $A_{L N}{ }_{j} R_{N} A^{-1} Y$, which yields the outputs of local industries required in region $j$ to produce the national goods for which region $j$ is responsible.

However, these outputs of local industries cannot be produced in region $j$ without in turn requiring inputs from local industries and hence requiring additional outputs from them. Thus, we have both direct and indirect requirements. Let $A_{L L}$ represent the set of input coefficients relating inputs of local industries to outputs of local industries. When we invert this matrix and multiply the inverted matrix $A_{L L}^{-1}$ by the term immediately above, we obtain $A_{L L}^{-1}{ }_{j} R{ }_{N} A^{-1} Y$. This last term yields the sum of the direct and indirect requirements, and thus that part of the outputs of 
local industries in region $j$ attributable to the required production of national goods.

But, in addition to this roundabout source of demand for the output of local industries in region $j$, there is the demand stemming directly and indirectly from the final demand for local goods within the region itself. This final demand represents that part of the local industry section of the national bill of goods for which a region is responsible, or, in short, what Leontief calls the "local bill of goods," ${ }_{j} Y_{L}$. Multiplying the local bill of goods by $A_{L L}^{-1}$, the inverse of the matrix $A_{L L}$ which relates inputs of local industries to outputs of local industries, we obtain $A_{L L}^{-1}{ }_{j} Y_{L}$. This yields the outputs of local industries required by the local bill of goods in region $j$. Hence, given the national final demand for all goods and the local bill of goods for region $j$, the outputs of local industries in region $j$, represented by the matrix ${ }_{j} X_{L}$, can be determined by the equation

$$
{ }_{j} X_{L}=A_{L L j}^{-1} Y_{L}+A_{L L}^{-1} A_{L N} R_{N} A^{-1} Y
$$

Through this model, the differential regional impact of a change in the national bill of goods, $Y$, is traceable.

The limitations and assumptions of the model should be kept clearly in mind. Some stem from the lack of data while others are of a more restrictive nature. For longer-run analysis, the assumption of constant regional proportions of the output of national industries can be adjusted partially to take account of such locational shifts as comparative cost studies and substitution analysis may suggest. For short-run analysis, we need more detailed information on the variation in proportions that takes place with change in the level of national output of a particular commodity.

The input coefficients which enter into all the matrices are not regionally differentiated (as they are in practice). For example, the set of coefficients describing the inputs of various commodities per dollar's worth of a national commodity like steel are the same whether the steel is produced in Fontana, California, or Pittsburgh, Pennsylvania. Also, the input coeffcients relating the outputs of local industries to the outputs of other local industries are likewise not regionally differentiated, though, where the information is available, such regional differences in production practice could be incorporated.

The difficulties of bringing households into the system of 
structural equations have been discussed elsewhere. ${ }^{36}$ In addition, the model assumes that regional consumption patterns are alike when in fact they may differ significantly.

The outflows of national goods from each region are not, in this model, related directly to inflows of the same goods to other regions. Neither inflows nor outflows for a given region are distinguished in terms of region of origin or destination. Hence, while differential regional reactions to hypothesized changes in the national bill of goods are obtained, the interregional relations are not made explicit.

\section{The interregional model}

The foregoing model was essentially concerned with the derivation of the regional implications of a given national projection. The alternative model discussed below ${ }^{37}$ poses a different basic question. It asks, What are the national implications of regional projections?

National aggregates of particular quantities can be viewed as the end result of the operations and interactions of the many components. These components are not directly affected by aggregates. They receive their stimuli through particularized channels (though, to be sure, these stimuli are reflected in the aggregates). National input-output systems are specifically designed to shed light on these channels. The preceding model does so to a still greater extent when it distinguishes between particular types of industries: local, regional of various orders, and national.

Ideally we should trace the connecting links between every producer and consumer in the system. Operational considerations, however, require spatial aggregation as well as industrial aggregation. The interregional model discussed here is advanced as a technique for using only a partial spatial aggregation in an effort to make explicit certain major spatial interrelations. The national economy is divided into meaningful regions, but no distinction is made between classes of commodities. Instead, each component in the system is grouped with others according to

\footnotetext{
${ }^{36}$ Leontief, "Exports, Imports, Domestic Output, and Employment," op.cit.

${ }^{87}$ The full presentation of this model is contained in W. Isard, "Interregional and Regional Input-Output Analysis: A Model of a Space-Economy," Review of Economics and Statistics, Vol. xxxm, November 1951, pp. 318-28.
} 
similarity of input-output characteristics and location (region, in this case).

Distinguishing productive processes on a basis of location as well as of technology is realistic. In national input-output analysis, industrial processes are classified according to similarity of relationship with other sectors of the economy. But industries having different supply areas and market areas do not have similar relationships with other sectors of the economy regardless of their technical similarity. Inputs of brick to the California construction industry are not "bricks," but "California bricks"; and an expansion of output on the part of the construction industry in New York will not cause the same output reaction in the brick industry in California as in the brick industry in Pennsylvania. On the basis of this and similar considerations, it is inadequate to group components of an economy simply by reference to technical requirements alone. They must also be grouped on a geographical basis.

These considerations lead to the construction of an input-output system in which a given activity in one region and the same activity in another region are considered different industries. The number of industries in the national economy then increases many times, being equal to the number of economic activities in each region summed over all regions. Given $n$ regions and $m$ economic activities, the set of structural equations becomes

$$
\begin{gathered}
{ }_{k} X_{i}-\sum_{l=1}^{l=n} \sum_{j=1}^{j=m}{ }_{k l} a_{i j l} X_{j}={ }_{k} Y_{i} \\
(i=1,2, \ldots, m ; k=1,2, \ldots, n)
\end{gathered}
$$

where ${ }_{k} X_{i}$ is the output of industry $i$ in region $k ;{ }_{l} X_{j}$ is the output of industry $j$ in region $l ;{ }_{k l} a_{i j}$ is the input coefficient representing the amount of input of industry $i$ in region $k$ per unit of output of industry $j$ in region $l$; and ${ }_{k} Y_{i}$ is the final (bill of goods) demand for the output of industry $i$ in region $k$.

Such a model focuses attention on commodity flows among regions. To be operational, it requires information on the source and destination of each commodity moving in interregional trade. The model does not imply any distinction between "national" and "local" industries. However, where regions are demarcated according to the criteria developed earlier, the larger the regions, the fewer the interregional flows and the less the information required on the origin and destination of specific commodities. 
Hence difficulties in determining the necessary information on interregional commodity flows are a significant factor in limiting the extent to which spatial detail can be retained in this model, and the degree to which spatial interrelations can be made explicit.

Once the degree of aggregation has been determined, the appropriate regions demarcated, and the bill of goods specified, the operation of the model is similar to that of a national inputoutput model. Since the bill of goods is specified by regions as well as by industries, national totals are only a summation of the interareal and interindustrial adjustments to projections of regional data. Theoretically, within the limitations of the assumptions, the model reveals "... . how a given autonomous impulse in one region is transmitted to other regions. It can show implicitly how the distance separating regions modifies the impact of this impulse and how the direct and indirect effects play back and forth (instantaneously) from region to region, constantly damped by spatial resistance." ${ }^{\text {s }}$

The limitations of the assumption of constant production coefficients have been discussed elsewhere. ${ }^{39}$ The additional implications of the assumption of constant coefficients for an interregional model require mention here.

Where constant coefficients refer both to an industry and to the location of that industry, constant geographic patterns of supply are required. Thus regional boundaries must be properly selected to reveal meaningful interregional flows. The requirement of constant geographic patterns of supply also implies comparative stability of relative prices, since major changes in relative prices will in many instances induce changes in the pattern of flows. In a territory in which regions are closely linked by modern methods of communication and transportation and the price system is relatively free to operate, the price relations among regions are likely to be comparatively stable. However, when major political boundaries intervene, as on an international level of analysis, institutional obstructions to the operation of a price system may arbitrarily alter market areas and supply channels.

The assumption of constant coefficients (constant supply channels, in this context) involves an additional restriction even where

38 ibid., p. 328.

30 Leontief, The Structure of American Economy, 1919-1929, as cited, pp. $38-41$ 


\section{REGIONAL AND NATIONAL PRODUCT}

relative prices are comparatively stable. "Any change in an item of the bill of goods directly calls for a proportional change in each of the inputs required in the production of that item."40 In terms of changes in a given input requirement, if the input is obtained from more than one region, this implies no change in the relative ability to compete of each of the several regions in supplying that input.

These limitations should not be exaggerated, however. If small changes in the bill of goods are postulated, and if there is excess capacity in the system, the error will be small. In addition, goods which have high transport costs or are otherwise regionally differentiated do have fairly stable market areas. Lastly, if locational studies suggest shifts in supply channels of the inputs for certain goods, these shifts can be approximated by directly entering the inputs by industry and region into the bill of goods.

An important aspect of the interregional model lies in its ability to make allowance for regional differences in production techniques and consumption patterns. (When information on such differences is not available, national coefficients may be used as approximations.) When such regional differences are registered in the model, they are useful in revealing the impact of changes in the bill of goods upon national and regional outputs. The interregional model can be regarded in one sense as yielding a finer industrial breakdown of a national input-output model. Input coefficients are necessarily index numbers in any system of aggregates, and the introduction of regional differentiation in these coefficients presumably reduces the deviation of actual coefficients around the separate indexes. At the same time, the increased number of coefficients permits the expression of a greater number of functional relations. Both factors tend to increase the accuracy of the analysis.

In the pursuit of regional and interregional analysis, the whole range of input-output techniques plays an integral part. It is not simply a matter of selection of one input-output model rather than another. They are all supplementary. Working with the data from a national input-output table is the most direct way to derive input coefficients. The use of these coefficients to obtain rough estimates of state consumption data from state production data yields invaluable information on the types of commodity

40 Isard, "Interregional and Regional Input-Output Analysis: A Model of a Space-Economy," op.cit. 
flows to be expected and on the subsequent demarcation of meaningful regions. The balanced regional model yields concrete evidence for testing the adequacy of regional boundaries and for devising a hierarchy of regions. Information yielded by this model, used in conjunction with available information on commodity flows, is very helpful in allocating these flows by industry and region of origin and destination.

In another sense, the balanced regional model and the interregional model discussed here are not mutually exclusive. Both are an attack on the same problem from different points of view and, as such, exert a mutual check. The balanced model yields estimates of the regional implications from national projection; the interregional model yields estimates of national implication from regional projections. A priori there is no basis of preference. Both are operational. Both have limitations at different points. Perhaps they should be considered not as alternatives, but as part of the same analytic set of tools for the problem of regional projections.

\section{H. SUMMARY}

1. We have pointed out some of the problems in deriving the regional implications of national product projections. These problems include all those involved in the projection of any of the other components of GNP. In addition, they include those which result from the fact that shifts in interindustrial relations and consequent alterations in the interindustrial flow of resources are not independent of similar shifts in interregional relations and the geographic flow of resources.

2. Regional projections using techniques like those used by the Council of Economic Advisers for GNP projections are inadequate without substantial modification. Extrapolation of past relationships between regional gross product and national gross product is extremely weak. The application of national rates of change to regional data for the projection of regional quantities is inadmissible except in the unusual case where these parameters are the same or nearly the same for all regions. Regional projections based on historically derived regional parameters may have a higher degree of validity for any given region. There is little likelihood, however, that the summation of a set of regional projections so derived will be consistent with a national projection directly obtained from national data. Such regional 
projections do not take into account the interregional reactions implicit in national projections.

3. Section C, on "Regional Projections: Interregional Reactions," represents an attempt to meet this problem within the framework of CEA methodology by associating growth in one region with growth in another. The simple linking of growth factors is inadequate when more than two regions enter the projection, since economic relations among regions depend not only on their industrial structures, but also on the distances separating them. The concept of income potential is suggested as a possible tool for incorporating the various effects of distance into one rough measure. The resulting model displays the change in any GRP as a function of internal plus external changes, the effect of any external change being modified by the distance at which it occurs. The interregional relations embraced by income potentials may be modified by $\beta$ coefficients to allow for the effects of particular regional resource structures.

4. The admission of the distance element into the analysis leads to consideration of commodity flows. Examination of these flows into and out of various states reveals a number of regularities and certain striking contrasts. Detailed analysis of these flows can shed considerable light on the nature of interregional relationships, and a rigorous technique for the derivation of regional projections would make full use of such analysis. Shifts in the composition of interregional commodity flows (and, correspondingly, interregional relationships) can be handled in terms of orthodox substitution analysis, or as substitution between transport outlays and other outlays, or as substitution among distance inputs, depending upon the actual circumstances. While it is difficult to envisage a regional projection based upon the projection of every type of commodity flow, substitution analysis can provide a basis for the explanation and projection of shifts in "strategic" flows. Thus it can serve as a useful supplement to other techniques.

5. As an alternative technique for regional projection, it is possible to devise a model in which some aspects of CEA methodology are preserved but with a lesser degree of aggregation. This method pays attention to the industrial composition of the regions. Regional gross product is disaggregated into the product of three major categories of economic activity. These are primary, secondary, and tertiary industries, which are also cross-classified 
as local or interregional. Coupling income potential, shift coefficients (representing employment shifts among these types of industry), and productivity change and population growth parameters with this system of aggregates yields a fairly comprehensive interregional projection model. This model is capable of incorporating and yielding information on such long-run interdependent phenomena as population growth, interregional population migration, rural-to-urban population shifts, gradually changing patterns of resource use, and consequent geographic shifts of industry.

6. Central to the problem of regional projections is the proper definition of a region. In our view, the concept of a region is an analytical tool. It is a set of criteria to guide the aggregation of economic activities situated at different points in space. From this point of view, there can be no absolute definition of a region. The criteria selected for demarcation of regional boundaries will vary with the needs of the analyst. As a concept, the region can be defined in perfectly general terms compatible with the needs of all disciplines. For the economist, the concrete definition of a region is tied to an understanding of the role of space in the economic system. Theoretical and empirical considerations suggest that distance acts to create a natural spatial agglomeration of economic activities around foci of varying order of magnitude. This implies a hierarchical order of regions, distinguishable by the nature of the commodity flows across the boundaries selected for demarcation. This orderliness is, however, considerably complicated by major commodity flows resulting from inequalities in resource endowment. Again, this serves to emphasize the necessity of detailed examination of interareal commodity flows in attempting to deal with any problem where economic activities are geographically differentiated.

7. The regional concept and flow analysis can be explicitly introduced into conventional input-output analysis. This can be accomplished with two general types of model. For convenience, we label that developed by Professor Leontief the "balanced regional model" and that developed by Isard the "interregional model." The former may be viewed as an attempt to yield in detail the regional implications of hypothesized shifts in the composition of the national bill of goods. The latter, by contrast, may be considered as an effort to determine the over-all national implication of economic growth and development in the several 


\section{REGIONAL AND NATIONAL PRODUCT}

regions. Both approaches utilize information on commodity flows and can incorporate information on geographic differences in production practice and consumption pattern.

8. Empirical analysis of the effects of the space factor in an interdependent economy is still in its infancy. An adequate approach to the problem of regional projections really implies the prior solution of a great many theoretical and empirical problems. The approaches touched upon in this paper are, therefore, to be considered primarily as suggested areas for further research. 